\title{
Exploring Knowledge and Self-Care Practice Toward Skin Aging and Sun Protection among College Students in Sulaimani City-Iraq
}

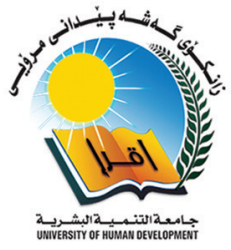

\author{
Hezha O. Rasul'1, Diary I. Tofiq ${ }^{1}$, Mohammad Y. Saeed ${ }^{2}$, Rebaz F. Hamarawf ${ }^{1}$ \\ ${ }^{1}$ Department of Chemistry, College of Science, University of Sulaimani, Iraq, ${ }^{2}$ Department of \\ Medicine, College of Medicine, University of Sulaimani, Iraq
}

\section{A B S T R A C T}

Several studies have been performed internationally to assess the understanding and self-care exercise of people in the direction of sun exposure and sun protection measures, as self-care is an essential pillar of public health. Nevertheless, limited data on these factors are available from the Middle East. The aim of this study was to investigate the students' awareness of skin aging and sun-protection measures among college students. For this purpose, a cross-sectional questionnaire was specially designed; a random sample of the students in the different college of the University of Sulaimani was selected. Data were collected between January and May 2017. The relationship between the skin cancer awareness and different sociodemographic characteristics was produced by applying multiple logistic regressions. The questionnaires were distributed to 450 college students. A total of 413 questionnaires had been completely responded and covered within the data analysis, with a response rate of $91.7 \% .41 \%$ of the respondents were females and $61.0 \%$ of the participants were aged between 18 and 21 years old. $47 \%$ have been privy to the association between sun exposure and skin aging. The respondents had been more likely to be aware of the connection between sun exposure and skin cancer $(P<0.03)$. The respondents from the third class of undergraduates were more likely to be familiar $(P<0.04)$. Staying under the shade during the outdoor activity was reported by more than $90 \%$ of our participants and is positioned as the most frequently used sun protection method.

Index Terms: Skin Aging, Skin Cancer, Skin Care, Sunscreen

\section{INTRODUCTION}

It is commonly agreed that certain people look "young for their age" or "old for their age." Moreover, the two common processes that influence skin aging are the skin aging that genetically determined and happens by passing time which is named chronologically (or intrinsic) skin aging process, while premature (or extrinsic) skin aging process is triggered

\section{Access this article online}

DOI: 10.21928/uhdjst.v2n1y2018.pp1-7

E-ISSN: 2521-4217

P-ISSN: 2521-4209

Copyright $\odot 2018$ Hezha O. Rasul, et al. This is an open access article distributed under the Creative Commons Attribution Non-Commercial No Derivatives License 4.0 (CC BY-NC-ND 4.0) by environmental factors. Recognized environmental factors that lead to premature skin aging process are sun exposure, air pollution, and smoking. The extrinsic skin aging rate is different notably among ethnic groups and individuals, whereas for the intrinsic rate of skin aging this occurrence does not relate [1]-[4].

Over the past decades, there has been a major growth in the instances of skin disease all over the world. Vital public health implications will occur when individual exposure to high cumulative levels of ultraviolet (UV) radiation [5], [6]. Unprotected and excessive sun exposure can damage skin cells, influence the normal growth of the skin and as a result cause several skin diseases such as burning and tanning. In addition, severe skin problems can occur when humans are

\section{Corresponding author's e-mail: Hezha O. Rasul, Department of Chemistry, College of Science, University of Sulaimani, Iraq. E-mail: hezha.} rasul@univsul.edu.iq

Received: 11-09-2017 Accepted: 05-02-2018 Published: 25-05-2018 
exposed to large quantities of solar UV radiation, including skin aging, pigmentary changes, and skin cancer [7]-[11].

UV radiation is the most important environmental factor which leads to premature skin aging [2]. Human beings are exposed to massive portions of UV radiation in part through numerous sources which include living and traveling in sunny climates and outdoor activity, additionally due to thinning of the ozone layer within the stratosphere [5]. The harmful effect of UV radiation on the skin look regarding facial aging was previously discovered in the end $19^{\text {th }}$ century by the two dermatologists Unna and Dubreuilh [12], [13]. Harry Daniell, in 1971, discovered the associations between cigarette smoking and skin aging [14]. Moreover, moderate alcohol consumption has also been shown to correlate with skin appearance [15]. Recent observation reported that air pollution is another significant environmental factor, which influences the skin appearance and leads to skin aging intrinsically [16]. Skin cancer has increased gradually during the past 50 years. Epidemiological studies demonstrate that skin cancer is developed by the sun, which is considered as the main considerable environmental factor which influences the skin. To reduce the skin cancer occurrence, the first step needs to be done increasing levels of awareness and self-care knowledge of the sun's harmful effects and how to better protect from solar emission [5], [17], [18]. It is essentially important to focus on educational level; this is with the purpose of changing behavioral patterns and protecting people against the dangerous effects of the sun [17]. Education plays a key role in raising awareness [19], [20]. Several types of research have been studied in different countries to determine people knowledge levels about the sun effect on facial aging and awareness level concerning sun protection [21].

In local skin care hospital, we have observed that many patients do not protect themselves from the sun and report unhealthy attitudes toward this subject. Exploring deficits in sun protection awareness and self-care practice toward different environmental factors can serve as a starting point for primary prevention interventions. Identifying knowledge and self-care practices of the public regarding skin aging, exposure and protection of the sun have been studied in several countries. Nevertheless, there is no study regarding this issue in Sulaimani city-Iraq. The purpose of the following study is to find out the levels of knowledge and self-care practice in regard to skin aging, sun exposure, and protection among college students. In addition, we will present the student's knowledge about various environmental factors such as air pollution, smoking, and drinking alcohol on skin aging.

\section{MATERIALS AND METHODS}

A cross-sectional survey was carried out between January 2017 and May 2017, both males and females students were involved at different colleges of Sulaimani University. From each college, several departments were selected randomly. A total of 413 questionnaires were collected. Data collection was performed by several trained students. The data collection process in this study was carried out using the questionnaire, which was specially created throughout a search of appropriate literature [1], [5], [7]. The re-designed questionnaire was tested initially in Sulaimani Center for Dermatology and Venereal Disease-Teaching Hospital to estimate approximately the length of the questionnaire in minutes, verify the participant's interpretation of questions and develop the questionnaire consequently. These questionnaires were tested in independent data sets, but these candidate questionnaires were excluded from the concluding analysis. However, the final version of the survey was conducted in the University of Sulaimani. The final version of the questionnaire included 24 questions and required approximately 5 minutes to complete. Approval from the Ethics Committee of University of Sulaimani, Sulaimani, Iraq, was obtained. The self-administered questionnaire was composed of three sections. The first section of the questionnaire comprised nine questions about personal information, such as university level, residence (urban vs. rural), gender, age, marital status, weight, high, smoking, and drinking alcohol. Various questions were integrated into the second part of the questionnaire about the student's knowledge concerning the factor of skin aging, sun's benefits and harmful effects on the skin and use of sun protection methods. The data were analyzed using Statistical Package for the Social Sciences Program (SPSS) version 21. After that the statistical assessment of data and the summarization of frequencies and percentages, multiple logistic regressions were used. Statistical significance was defined as $P<0.05$.

\section{RESULTS}

The questionnaire was distributed to 453 . A complete data from 413 participants were returned and integrated into the analysis with a $91.7 \%$ response rate. There was a various range of age of the students who participated in the survey, $61.0 \%(252 / 413)$ of the respondents were aged $18-21$ years old, while, and $34.1 \%(141 / 413)$ of the students were aged between 22 and 25. Only 4.8\% (20/413) of the participants were aged over 25 years. In addition, 58.6\% (242/413) of the students who contributed to the survey were male, 
while $41.4 \%(171 / 413)$ of the participants were female. The sociodemographic characters of the research population are depicted in Table I.

The level of awareness among students regarding unprotected exposure to the sun caused skin damage is illustrated in Table II. This study has indicated that the majority of respondents were mindful that excessive sun exposure causes skin burn $(87.9 \%, 363 / 409) .47 \%(194 / 402)$ reported that sun exposure can cause skin aging, while almost more than

\begin{tabular}{lc}
\multicolumn{2}{c}{ TABLE I } \\
\multicolumn{2}{c}{ Sociodemographic data of the $\mathbf{4 1 3}$ participants } \\
\hline Characteristics & Count (\%) \\
\hline Gender & \\
Male & $242(58.6)$ \\
Females & $171(41.4)$ \\
Age (years) & \\
18-21 & $252(61.0)$ \\
$22-25$ & $141(34.1)$ \\
Over 25 & $20(4.8)$ \\
Marital status & \\
Single & $377(91.3)$ \\
Married & $32(7.7)$ \\
Residence & \\
Urban & $249(60.3)$ \\
Rural & $162(39.2)$ \\
Education (undergraduate) & \\
Class 1 & $137(33.2)$ \\
Class 2 & $113(27.4)$ \\
Class 3 & $65(15.7)$ \\
Class 4 & $85(20.6)$ \\
\hline The denominator is different among variables due to missing values
\end{tabular}

\begin{tabular}{|c|c|c|c|}
\hline \multicolumn{4}{|c|}{$\begin{array}{c}\text { TABLE II } \\
\text { Awareness of negative effects of the sunlight } \\
\text { among respondents }\end{array}$} \\
\hline & \multicolumn{3}{|c|}{$n(\%)^{\mathrm{a}}$} \\
\hline & Yes & No & Don't know \\
\hline \multicolumn{4}{|c|}{ What damage does excessive sun-exposure cause? } \\
\hline Skin burn & $363(87.9)$ & $18(4.4)$ & $28(6.8)$ \\
\hline Skin aging & $194(47.0)$ & $74(17.9)$ & $134(32.4)$ \\
\hline Skin cancer & 217 (52.5) & $62(15.0)$ & $125(30.3)$ \\
\hline
\end{tabular}

a half of respondents $(52.5 \%, 217 / 404)$ were responsive of the relationship between skin cancer and sun exposure. Nevertheless, the level of knowledge of students regarding the impact of sunlight on skin was explored; understanding of the relationship between synthesis of Vitamin D and sun exposure was the most well-known benefit of the students, with $76.1 \%$ of the male and $70.7 \%$ of the female citing it. The male and female participants were reported (74.4\% and $70.6 \%$, respectively) regarding the association between sun exposure and treatment in some skin conditions. The relationship between positive psychological effects sun exposure was recorded $63 \%$ in male respondents, while only $37.0 \%$ of the female participants were aware of this relation, as shown in Table III.

The logistic regression models were used to assess the relationship between the demographic factors influencing awareness of the connection between sun exposure, and skin cancer is shown in Table IV.

Students aged 18-21 years reported higher rates of skin cancer knowledge $(P<0.025)$. Similarly, respondents from Class 3 were more likely to be linked with the understanding of the association between sun exposure and skin cancer $(P<0.037)$. However, there was no significant dissimilarity found in awareness between students rooted in their gender, marital status, or area of residence (rural vs. urban).

The sun protection behaviors among respondents are summarized in Table V. $56 \%$ of study students reported that they were protecting themselves during the daytime against the effects of the sun by wearing sun protection cream $(232 / 401)$, wearing sunglasses $(61.9 \%, 256 / 401)$, and light-colored cotton clothes $(83.1 \%, 343 / 407)$. Wearing "a hat" was found to be the least frequently used the technique of sun protection $(40.2 \%, 166 / 391)$. The preferred method of protection during their outdoor activities was staying in the shade and inside with the data $(90.6 \%, 374 / 406)(87.9 \%$, $363 / 404)$, respectively. In addition, $87.9 \%(363 / 404)$ of participants reported that they were trying to stay inside to protect their skin from the sunlight. Data on using anti-aging

\begin{tabular}{|c|c|c|c|c|}
\hline \multicolumn{5}{|c|}{$\begin{array}{c}\text { TABLE III } \\
\text { Students' levels of knowledge about beneficial effects of the sunlight }\end{array}$} \\
\hline Factor & \multicolumn{2}{|c|}{ Male, $n(\%)$} & \multicolumn{2}{|c|}{ Female, $n(\%)$} \\
\hline Synthesis of Vitamin D & $181(76.1)$ & $57(23.9)$ & $118(70.7)$ & $49(29.3)$ \\
\hline Treatment in some skin conditions & $177(74.4)$ & $61(25.6)$ & $115(70.6)$ & $48(29.4)$ \\
\hline Positive psychological effects & $133(63.0)$ & $104(56.5)$ & $78(37.0)$ & $80(43.5)$ \\
\hline
\end{tabular}


skin product among our respondents showed that just about $55 \%$ of the female students reported that they never used anti-aging cream. Of respondents, only $45.1 \%(60 / 133)$ and $31.1 \%(60 / 183)$ of the female and male, respectively, had ever used sunscreen anti-aging product.

In addition, the students were asked about the importance of looking after their skin. As illustrated in Fig. 1, a surprising result had been recorded in this section, most of the students reported that it is important to look after their skin.

In this study, the participants were asked about their concern for various issues relating to the premature skin aging such. According to the data, stress was the most concerned respond, and the majority of students were submitted their choice to less concerned about sun exposure as shown in Table VI.

Perceptions of key factors of aging among students were recorded, and poor diet was considered as the main factor of aging among the students (33.1\%) as shown in Table VII.

\begin{tabular}{lcc}
\multicolumn{2}{c}{ TABLE IV } \\
$\begin{array}{l}\text { Logistic regression analyses of skin cancer } \\
\text { awareness and sociodemographic characteristics }\end{array}$ \\
\hline & $\boldsymbol{P}$ value & $\begin{array}{c}\text { Odds ratio } 95 \% \mathbf{~ C l} \\
\text { (lower bound-upper bound) }\end{array}$ \\
\hline Male & 0.082 & $0.624(0.367-1.061)$ \\
Age 18-21 years & 0.025 & $5.992(1.255-28.603)$ \\
Single & 0.196 & $0.514(0.188-1.410)$ \\
Urban & 0.268 & $1.333(0.802-2.217)$ \\
Class 3 & 0.037 & $0.427(0.192-0.949)$ \\
\hline
\end{tabular}

$\mathrm{Cl}$ : Confidence interval

\begin{tabular}{|c|c|c|c|}
\hline \multicolumn{4}{|c|}{$\begin{array}{c}\text { TABLE V } \\
\text { Respondents applied sun protection methods }\end{array}$} \\
\hline & \multicolumn{3}{|c|}{$n(\%)^{a}$} \\
\hline & Regularly & Never & Sometimes \\
\hline \multicolumn{4}{|c|}{$\begin{array}{l}\text { Which of the protection methods do you often use during the } \\
\text { daytime? }\end{array}$} \\
\hline $\begin{array}{l}\text { Wear sun } \\
\text { protection } \\
\text { cream }\end{array}$ & $81(19.6)$ & $169(40.9)$ & $151(36.6)$ \\
\hline Wear hat & $24(5.8)$ & $225(54.5)$ & $142(34.4)$ \\
\hline $\begin{array}{l}\text { Wear } \\
\text { sunglasses }\end{array}$ & $89(21.5)$ & $14(35.1)$ & $167(40.4)$ \\
\hline $\begin{array}{l}\text { Wear light } \\
\text { cotton clothes }\end{array}$ & $92(22.3)$ & $64(15.5)$ & $251(60.8)$ \\
\hline $\begin{array}{l}\text { Stay under } \\
\text { shade }\end{array}$ & $137(33.2)$ & $32(7.7)$ & 237 (57.4) \\
\hline Stay inside & $113(27.4)$ & $41(9.9)$ & $250(60.5)$ \\
\hline
\end{tabular}

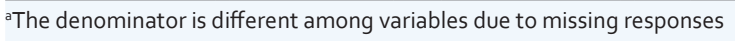

\section{DISCUSSION}

Information about public knowledge and behaviors regarding skin aging and protection measures among Kurdish people are little, and none official study in Kurdistan was found after a broad literature review on this topic. Diverse climate conditions can be found in different regions of Iraq. The Northern part of Iraq, which is called Kurdistan, has a cooler atmosphere than the southern part. The climate of Kurdistan has distinct high temperatures in day-time and low temperatures during the nighttime. From June to September, daytime temperatures reach $44^{\circ} \mathrm{C}$ or higher throughout the area. The south has higher temperatures, which can go as high as $48^{\circ} \mathrm{C}$ during summer time. In our local clinical dermatology center, we noticed that various sun's related skin diseases such as sunburn are more common in the summer period because the weather in the summer is exceptionally hot.

There has been an important increase in the incidence of the skin cancer over the past few decades. In addition, it has been shown that developing this condition is related to over a lifetime commutation of sun exposure [22].

It has been reported that with the implementation of sun protection measures and proper behaviors approximately around $80 \%$ of skin cancer cases can be prevented. Nevertheless, the occurrence of skin cancer is still increasing [23]. This study has indicated that more than $90 \%$ of our study respondents they commonly stayed under the shade to avoid the harmful effects of sun exposure. Gray et al. and Ergin et al. achieved a similar result in their 2012

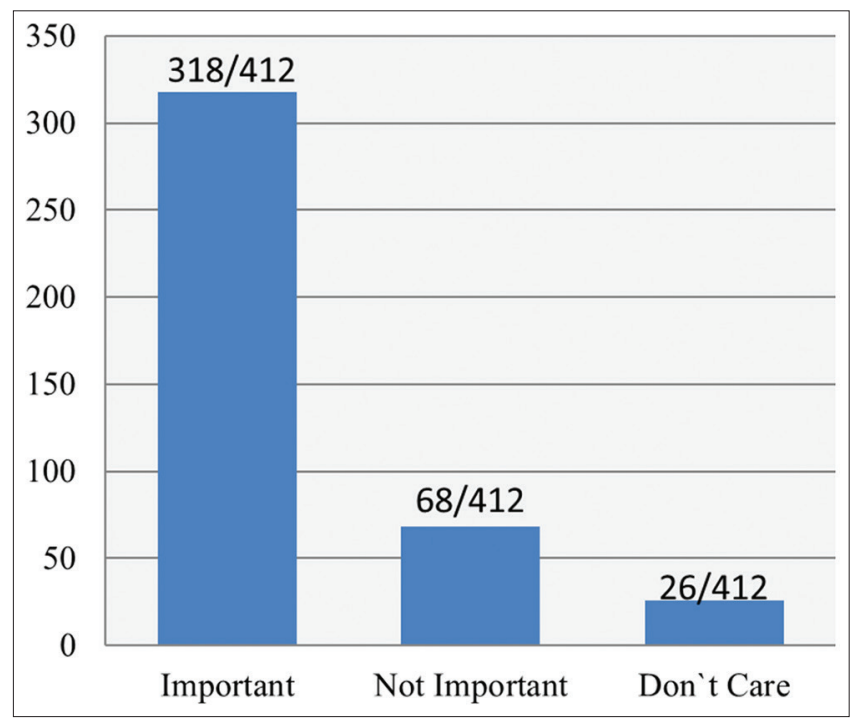

Fig. 1. How Important is to look after the skin?

UHD Journal of Science and Technology | May 2018 | Vol 2 | Issue 1 


\begin{tabular}{|c|c|c|c|}
\hline \multicolumn{4}{|c|}{$\begin{array}{l}\text { TABLE VI } \\
\text { Participants concern about issues relating to } \\
\text { skincare }\end{array}$} \\
\hline & \multicolumn{3}{|c|}{$n(\%)$} \\
\hline & Concerned & Not concerned & Missing-value \\
\hline \multicolumn{4}{|c|}{ Premature aging caused by } \\
\hline $\begin{array}{l}\text { Sun } \\
\text { exposure }\end{array}$ & $248(60.0)$ & $159(38.5)$ & $6(1.5)$ \\
\hline Stress & $347(84.0)$ & $63(15.3)$ & $3(0.7)$ \\
\hline $\begin{array}{l}\text { Lack of } \\
\text { sleep }\end{array}$ & $303(73.4)$ & $106(25.7)$ & $4(1.0)$ \\
\hline Smoking & 339 (82.1) & $70(16.9)$ & $4(1.0)$ \\
\hline $\begin{array}{l}\text { Drinking } \\
\text { alcohol }\end{array}$ & $299(72.4)$ & $108(26.2)$ & $6(1.5)$ \\
\hline
\end{tabular}

\begin{tabular}{|c|c|c|}
\hline \multicolumn{3}{|c|}{$\begin{array}{c}\text { TABLE VII } \\
\text { Key factors of skin aging }\end{array}$} \\
\hline $\begin{array}{l}\text { Main factor of } \\
\text { aging }^{\text {a }}\end{array}$ & $\begin{array}{c}\text { Responses } \\
n(\%)\end{array}$ & Percent of cases $(\%)$ \\
\hline Sun & $97(14.9)$ & 24.3 \\
\hline Weather & $156(24.0)$ & 39.1 \\
\hline Pollution & $181(27.9)$ & 45.4 \\
\hline Poor diet & $215(33.1)$ & 53.9 \\
\hline Total & 649 (100.0) & 162.7 \\
\hline
\end{tabular}

Dichotomy group tabulated at value 1

and 2011 study, respectively [5], [24]. Despite the fact that, Kokturk et al. and Kaymak et al. found that staying inside at peak times to be the most commonly practiced method of avoiding the harmful effects of the sun, with $53 \%$ and around $45 \%$ for women and men [18], [25]. Approximately $52 \%$ of the respondents reported awareness of the link between sun exposure and the hazard of skin cancer, which is comparable to the previous study carried out in Saudi Arabia by AlGhamdi et al. and Al Robaee [7], [26]. However, this level of awareness is considered to be lower than similar studies conducted in the western community. For instance, the relationship between sun exposure and skin cancer was made by study participants in Malta with figures of $92.5 \%, 92 \%$ in the United States, $90 \%$ in Australia, and 85\% in Canada [27]. The outcome of this study has shown that around $88 \%$ of study participants were familiar with the linkage between the sun and skin burn. Furthermore, knowledge of respondents about the connection between sun exposure and skin aging was confirmed with $47 \%$. In this study, the participants were questioned about their levels of knowledge of the benefits of the sunlight; slight gender distinction was noted in answer to the positive effect of the sun on the synthesis of Vitamin $\mathrm{D}$ and treatment in several skin conditions. It was found that $76.1 \%$ of the male was aware of the positive effect of the synthesis of Vitamin D in comparison to $70.7 \%$ of the female. In addition, the results of well-known effects of treatment in some skin conditions were analyzed; these statistics were $74.4 \%$ for male and $70.6 \%$ for female.

Regardless of the reasonably superior information and awareness among our study participants that the sunlight predisposes people to several skin disorders, including skin aging, sunburn, and skin cancer, the rate of sunscreen attentiveness was low. This study reported that more than half of the participants wear sun protection cream. In addition, $40.9 \%$ of the respondents reported that they have never used sunscreen. The finding regarding the use of sunscreen has been cited by several studies on this subject matter [26], [28], [29]. Moreover, around $62 \%$ of students stated that they wear sunglasses as one of the sun protection methods. Nikolaou et al. reported that in Mediterranean population sunglasses was the most regularly used sun protection with the number of $83.4 \%$ [30]. As we have shown, protective clothes were used as sun protection among students, as $83.1 \%$ of respondents reported wearing light cotton clothes, and $40.2 \%$ of them reported using a hat during outdoor activities. Certainly, this rate of sun protection utilizes and knowledge among the Kurdish people as reported by this study is quite alarming and should spotlight the interest in this concern with regard to health education programs and future studies. Additional learning is needed as the knowledge only is not sufficient to make a transform in approach. Universities are ideal environment because of their existing infrastructure to help students attaining the essential healthy behaviors. Sun protection awareness and ideas can be integrated into the existing areas of study programs.

Nevertheless, this study has several potential limitations that should be reserved when interpreting the results. An expediency sample of students from only one university was surveyed. Therefore, caution must be kept in mind in expanding our findings to other universities, especially universities situated in other geographical regions. Another limitation to these findings is the reality that the students were asked to report their answers as yes or no with offered statements about sun exposure harmful effect including skin aging, skin burn, and skin cancer, which may prejudice responses and direct to a mistaken evaluation of the proportion of the public who have true and factual information of the sun side effects. Finally, the results of this study limited by cross-sectional character, which means that commands of effects can only be hypothesized. 


\section{CONCLUSION AND RECOMMENDATION}

This study has specified a low level of public knowledge and self-care practice among the college students regarding skin aging, the harmful effects of sun exposure and sun protection methods. In addition, this study has discovered that sun protection measure is commonly inadequate among students and on a regular basis only a small part of participants uses sunscreen. Therefore, this research highlights the requirement for the media, further studies and future well-being education programs to be utilized with the purpose of developing the implementation of sun protection behaviors including wearing sunscreen regularly and wearing protective clothes among the general public.

\section{ACKNOWLEDGMENT}

The authors would like to acknowledge Kale Rahim and Lano Hiwa from the University of Sulaimani for the data collection. We also thank the staff of the Sulaimani Center for Dermatology and Venereal Disease (Teaching Hospital) for their generous help.

\section{REFERENCES}

[1] H. Rexbye. "Influence of environmental factors on facial ageing". Age and Ageing, vol. 35, no. 2, pp. 110-115, 2006.

[2] A. Vierkötter and J. Krutmann. "Environmental influences on skin aging and ethnic-specific manifestations". Dermato-Endocrinology, vol. 4, no. 3, pp. 227-231, 2012.

[3] B. Gilchrest and J. Krutmann. Skin Aging. Springer, Berlin, 2006.

[4] R. Halder and C. Ara. "Skin cancer and photoaging in ethnic skin". Dermatologic Clinics, vol. 21, no. 4, pp. 725-732, 2003.

[5] E. Yurtseven, T. Ulus, S. Vehid, S. Köksal, M. Bosat and K. Akkoyun. "Assessment of knowledge, behaviour and sun protection practices among health services vocational school students". International Journal of Environmental Research and Public Health, vol. 9, no. 12, pp. 2378-2385, 2012.

[6] O. Tekbas, D. Evci, and U. Ozcan. "Danger increasing with approaching summer: Sun related UV rays". TAF Preventive Medicine Bulletin, vol. 4, no. 2, pp. 98-107, 2005.

[7] K. AlGhamdi, A. AlAklabi and A. AlQahtani. "Knowledge, attitudes and practices of the general public toward sun exposure and protection: Anational survey in Saudi Arabia". Saudi Pharmaceutical Journal, vol. 24, no. 6, pp. 652-657, 2016.

[8] B. Armstrong and A. Kricker. "The epidemiology of UV induced skin cancer". Journal of Photochemistry and Photobiology B: Biology, vol. 63, no. 1-3, pp. 8-18, 2001.

[9] R. MacKie. "Effects of ultraviolet radiation on human health". Radiation Protection Dosimetry, vol. 91, no. 1, pp. 15-18, 2000.

[10] M. Mabruk, L. Toh, M. Murphy, M. Leader, E. Kay and G.
Murphy. "Investigation of the effect of UV irradiation on DNA damage: Comparison between skin cancer patients and normal volunteers". Journal of Cutaneous Pathology, vol. 36, no. 7 , pp. 760-765, 2009.

[11] L. Scerri and M. Keefe. "The adverse effects of the sun on the skin-a review". Maltese Medical Journal, 7, pp.26-31, 1995.

[12] P. Unna. The Histopathology of the Diseases of the Skin. Clay, Edinburgh, 1896.

[13] W. Dubreuills, Des Hyperkératoses Circonscrites. Masson, Paris, 1896.

[14] H. Daniell. "Smoker's Wrinkles". Annals of Internal Medicine, vol. 75 , no. 6, pp. 873, 1971.

[15] E. Sherertz and S. Hess. "Stated Age". New England Journal of Medicine, vol. 329, no. 4, pp. 281-282, 1993.

[16] A. Vierkötter, T. Schikowski, U. Ranft, D. Sugiri, M. Matsui, U. Krämer and J. Krutmann. "Airborne Particle Exposure and Extrinsic Skin Aging". Journal of Investigative Dermatology, vol. 130, no. 12, pp. 2719-2726, 2010.

[17] T. Filiz, N. Cınar, P. Topsever and F. Ucar. "Tanning youth: Knowledge, behaviors and attitudes toward sun protection of high school students in Sakarya, Turkey". Journal of Adolescent Health, vol. 38, no. 4, pp. 469-471, 2006.

[18] Y. Kaymak, O. Tekbaş and S. Işıl. "Knowledge, attitudes and behaviours of university students related to sun protection". Journal of Turkish Dermatology, vol. 41, pp. 81-85, 2007.

[19] P. Cohen, H. Tsai and J. Puffer. "Sun-protective behavior among high-school and collegiate athletes in los angeles, CA". Clinical Journal of Sport Medicine, vol. 16, no. 3, pp. 253-260, 2006.

[20] T. Owen, D. Fitzpatrick and O. Dolan. "Knowledge, attitudes and behaviour in the sun: The barriers to behavioural change in Nothhern Ireland". The Ulster Medical Journal, vol.73, no. 2, pp. 96-104, 2004.

[21] A. Geller, L. Rutsch, K. Kenausis, P. Selzer and Z. Zhang. "Can an hour or two of sun protection education keep the sunburn away? Evaluation of the environmental protection agency's sunwise school program". Environmental Health, vol. 2, no. 1, pp. 1-9, 2003.

[22] R. Bränström, S. Kristjansson, H. Dal and Y. Rodvall. "Sun exposure and sunburn among Swedish toddlers". European Journal of Cancer, vol. 42, no. 10, pp. 1441-1447, 2006.

[23] N. Sendur. "Nonmelanoma skin cancer epidemiology and prevention". Turkiye Klinikleri Journal of Internal Medical Sciences, vol. 1, pp. 80-84, 2005.

[24] A. Ergin, I. Ali and I.B. Mehmet. "Assessment of knowledge and behaviors of mothers with small children on the effects of the sun on health". The Pan African Medical Journal, vol. 4, pp. 72-78, 2011.

[25] A. Köktürk, K. Baz and R. Buğdaycı. "Dermatoloji polikliniğine başvuran hastalarda güneşten korunma bilinci ve alışkanlıkları", Türk Klinical Dermatology, vol. 12, pp. 198-203, 2002.

[26] A. Al Robaee. "Awareness to sun exposure and use of sunscreen by the general population". Bosnian Journal of Basic Medical Sciences, vol. 10, no. 4, pp. 314-318, 2010.

[27] S. Aquilina, A. Gauci, M. Ellul and L. Scerri. "Sun awareness in Maltese secondary school students". Journal of the European Academy of Dermatology and Venereology, vol. 18, no. 6, pp. 670675, 2004.

[28] K. Wesson and N. Silverberg. "Sun protection education in the 
United States: What we know and what needs to be taught". Cutis, vol. 71, pp. 71-74, 2003.

[29] E. Thieden, P. Philipsen, J. Heydenreich and H. Wulf. "UV radiation exposure related to age, sex, occupation, and sun behavior based on time-stamped personal dosimeter readings. Archives of Dermatology, vol. 140, no. 2, 2004.
[30] V. Nikolaou, A. Stratigos, C. Antoniou, V. Sypsa, G. Avgerinou, I. Danopoulou, E. Nicolaidou and A. Katsambas. "Sun exposure behavior and protection practices in a Mediterranean population: A questionnaire-based study". Photodermatology, Photoimmunology and Photomedicine, vol. 25, no. 3, pp. 132-137, 2009. 